\title{
Correction to: A cell-cycle signature classifier for pan-cancer analysis
}

Neha Tabassum (D) - Theodora A. Constantin - Biancastella Cereser $(\mathbb{D} \cdot$ Justin Stebbing

Published online: 28 January 2021

(c) The Author(s), under exclusive licence to Springer Nature Limited 2021

Correction to: Oncogene

https://doi.org/10.1038/s41388-020-01426-5

In the original published version, the list of authors was incomplete. Theodora A. Constantin was missing, and Neha
Tabassum and Theodora A. Constantin share first authorship.

The correct author list is given above.

The original article has been corrected. 